\title{
IMPACT OF DEHYDROEPIANDROSTERONE IN PREVENTION OF PARACETAMOL INDUCED NEPHROTOXICITY IN RATS
}

\author{
Abbas O. Elkarib \\ Departement of Physiology, College of Medicine, King Khalid University, \\ P.O. Box 641. Abha, 61421, Kingdom of Saudi Arabia
}

Received 2014-03-10; Revised 2014-03-15; Accepted 2014-03-26

\begin{abstract}
Paracetamol (PCM) overdose can cause nephrotoxicity with oxidative stress as one of the possible mechanisms mediating the event. However, Dehydroepiandrosterone (DHEA), the major secretory product of the human adrenal gland, has been shown to possess a multi-targeted antioxidant activity which is also effective against lipid peroxidation induced in various animal models and against various human disorders. In this study, the preventive effect of DHEA against PCM-induced nephrotoxicity was examined. Rats were divided into four groups containing 10 rats each, as follows: A control: Received normal saline, Vehicle treated: Received the vehicle (5\% DMSO), PCM model (750 mg kg-1), PCM and DHEA treated: Received concomitant dose of PCM (750 mg $\left.\mathrm{kg}^{-1}\right)+$ DHEA $\left(250 \mathrm{mg} \mathrm{kg}^{-1}\right)$, respectively, for 4 consecutive weeks. All treatment were given orally to animals. Our results show that co-treatment of DHEA with PCM prevented the PCM-induced nephrotoxicity and oxidative impairments of the kidney, as evidenced by a significantly reduced $(p<0.05)$ level of serum creatinine, urea and BUN with parallel significant increases in serum protein, $\mathrm{Cr}$ clearance and kidneys weights. Furthermore, DHEA was able to induce a significant increment $(\mathrm{p}<0.05)$ of renal levels of reduced Glutathione (GSH) and activities of Superoxide Dismutase (SOD) and Glutathione Peroxidise (GPx). An effect that was accompanied with a significant decrease in renal lipid peroxides levels (MDA). The nephroprotective effects of DHEA was confirmed by a reduced intensity of renal cellular damage, as evidenced by histological findings. In conclusion, DHEA at a daily dose of $250 \mathrm{mg} \mathrm{kg}^{-1}$ has a protective role against PCM-induced nephrotoxicity in rats and the process is probably mediated through its antioxidant properties.
\end{abstract}

Keywords: Paracetamol, Nephrotoxicity, DHEA, Rats

\section{INTRODUCTION}

Paracetamol (PCM ) or Acetaminophen (marketed as Panadol in Great Britain, Tyelonol in the US) is an effective, well tolerated, widely used over-the-counter analgesic antipyretic agent (Jalan et al., 2006) with more than 1 billion tablets sold annually in the United States alone (Nourjah and Wiley, 2002). It was reported that PCM is safe when administered at recommended doses (Ozkaya et al., 2010). However, its overdose is commonly associated with hepatic (Toklu et al., 2006) and renal damages (Stern et al., 2005). It is estimated that over 56,000 emergency visits and nearly 500 deaths occur in the US annually, resulting from PCM toxicity, owing to either intentional or accidental overdoses
(Nourjah and Wiley, 2002). However, these figures continue to rise (Bernal, 2003). In recent time, the safety of PCM even at therapeutic doses has generated considerable debate (Jalan et al., 2006).

In the tissue, PCM toxicity is mediated by the activity of its reactive metabolite known as $N$-Acetyl- $P$ benzoquinoneimine (NAPQI), which is detoxified by intracellular Glutathione (GSH) (Elhabib et al., 2007). Therefore, an overdose of PCM will saturate the conjugation pathways of GSH and cause depletion of cellular GSH. This subsequently leads a reduced capacity of GSH to detoxify NAPQI. Increased level of NAPQI mediates oxidative damage and thus enhances cellular injuries and organ dysfunction, including renal damage (Hart et al., 1994). 
Although the occurrence of nephrotoxicity is less common than that of hepatotoxicity as reported by Blakely and McDonald (1995), PCM induced renal toxicity has been increasingly reported in many literature, (Boutis and Shannon, 2001; Abdel-Zaher et al., 2007; Gulnaz et al., 2010) and some studies have documented that PCM-induced renal tubular damage and acute renal failure can occur even in the absence of liver damage (Carpenter and Mudge, 1981) and can be the primary manifestation of PCM toxicity (Boutis and Shannon, 2001). In fact this is not surprising, probably because the kidney is supplied with a large volume of blood accounting for $20 \%$ of total cardiac output (Marieb, 2006). Therefore, the kidney is likely to be affected by secondary effects of drugs and their metabolites that are accumulated through the urine concentrating mechanism (Marieb, 2006). According to literature, PCM nephropathy is characterized by alterations in urine volume, glutathione status, creatinine clearance and increased products of lipid peroxidation (Boutis and Shannon, 2001).

However, therapeutic options for the treatment and the prophylaxis of acetaminophen-associated complications are limited (James et al., 2003a). Thus, the search for chemoprophylactic agents for acetaminophen related renal complications becomes imperative. Since current evidence suggests that PCM-induced hepatorenal injury is mediated by oxidative damage and increased lipid peroxidation (Schnellman, 2001; Bessems and Vermeulen, 2001). Therefore, the alternative treatments for PCM toxicity could be achieved using a natural compound with antioxidant activity. Indeed several biological compounds with antioxidant properties including melatonin, vitamin $\mathrm{E}$ and $\mathrm{N}$-acetyl-cysteine proved effective in protecting the kidneys against deleterious effects of PCM overdose (Sener et al., 2003)

Dehydroepiandrosterone (DHEA) and its sulphate metabolite (DHEAS) are the major steroid hormones secreted by the zona reticularis of the adrenal gland (Krysiak et al., 2008). A decline in their production is the most characteristic age-related change in the adrenal cortex (Krysiak et al., 2008; Kumar et al., 2008). It is a widely studied hormone with multifunctional properties. DHEA has been reported to possess beneficial effects on cancer (Boccuzzi et al., 1992), atherosclerosis (Gordon et al., 1988), obesity (Nestler et al., 1988) and diabetes (Coleman et al., 1982). Interstingly, DHEA was shown to protect agains I/R injury in kidney (Aksoy et al., 2004). Published data support that DHEA is well know antioxidant that acts to limit generation of free radicals and lipid peroxidation, in vivo as well as in vitro (Aragno et al., 1997; Brignardello et al., 1998; Kumar et al., 2008). From these finding, DHEA therapy in various diseases related to oxidative stress is an area of interest.

As, PCM is implicated to cause nephrotoxicity mainly by oxidative stress related mechanism, in the current study, we hypothesized that therapeutic dose of DHEA treatment could ameliorate or reduce the severity of oxidative damaged in PCM induced nephrotoxicty in rats. This hypothesis was studied by measuring kidney function markers, oxidative stress biomarkers, antioxidant status and histopathology structural changes in the kidneys of intoxicated rats.

\section{MATERIALS AND METHODS}

Paracetamol (PCM) as tablets were purchased from local medical store, Abha, Kindom of Saudi Arabia and dissolved in $0.9 \%$ normal saline to the desired final volume used in the experimental procedure. Dehydroepiandrosterone (DHEA) were purchased from Sigma Co (USA) and was prepared as a stock solution by dissolving in 5\% DMSO in normal saline. Assay kits for determination of Malondialdehyde (MDA, Cat No. NWK-MDA01) were purchased from NWLSS, USA. Assay kit for determination of superoxide Dismutase (SOD, Cat NO.706002), glutathione peroxidase activity (GPx, Cat NO.703102) and reduced glutathione (Cat NO.703002) were purchased from Cayman Chemical, MI, USA. Assay kit for determination of Urinary creatinine (Cat NO.500710 ) was purchased, Cayman Chemical Company, MI, USA). Kinetic reagent $\mathrm{s}$ for determination of blood urea nitrogen (BUN, Cat., no. 283-30) were purchased from Diagnostic Chemicals Limited. Spectrophotometrical assay kit for determination of serum Sodium $\left(\mathrm{Na}^{+}\right)$, Potassium and total protein $\left(\mathrm{K}^{+}\right)$ were purchased from Human diagnostic company, German. Assay colorimetric kit for determination serum and urinary Creatinine (Cr) concentration (Cat., no. 700460 \& Cat., no. 500701; respectively) were purchased from Cayman Company (Ann Arbor, MI, USA). All analyses were performed in accordance with the manuals provided by the manufacturers.

\subsection{Animals}

The experiments were performed on healthy male Wistar rats of eight weeks old and body weight of 190$200 \mathrm{~g}$. They were supplied from the animal house at the college of medicine of King Khalid University. The rats were fed with standard laboratory diets, given water $a d$ libitum and maintained under laboratory conditions of 
temperature $22^{\circ} \mathrm{C}\left( \pm 3^{\circ} \mathrm{C}\right)$, with $12 \mathrm{~h}$ light and $12 \mathrm{~h}$ dark cycle. The experimental procedures involving the handling and treatment of animals were approved by the ethical committee of the medical college at King Khalid University and all procedures were conducted in accordance with the National Institute of Health's Guide for the Care and Use of Laboratory Animals.

\subsection{Experimental Protocol}

After one week adaptation, animals were divided into 4 groups (each of 10 rats) and treated as follows:

- Group-I: Served as normal control received normal saline only daily

- Group-II: Served as vehicle treated received 5\% DMSO in normal saline three times/week

- Group-III: Served as PCM control, administered with paracetamol $750 \mathrm{mg} \mathrm{kg}^{-1}$ day on daily basis

- Group-IV: Serve as DHEA co-treated group received PCM as in group-II + DHEA (250 $\left.\mathrm{mg} \mathrm{kg}^{-1}\right)$ three time/week

Selection of PCM doses was based on previous published data that showed nephrotoxic effect of PCM at this dose and route of administration (Zariyantey et al., 2012) where as selection of DHEA was based on the published data that showed that chronic administration of DHEA at this dose and by this route is safe in rats and has a therapeutic and an antioxidant effect in various tissues (Lardy et al., 1999).

\subsection{Post Treatment Procedure}

All treatments were continued for 4 weeks on daily basis. Treatments were given to all groups orally with the help of feeding canula. During this period, the rats were weekly adapted to metabolic cages (These cages offer big space to rats to move freely without any restrained stress). At the end of day 28 and after a $12 \mathrm{~h}$ fasting, rats were placed in their metabolic cages and the and urine samples were collected into tubes containing $20 \mu \mathrm{L}$ of $2.5 \mathrm{~mol} \mathrm{~L}^{-1} \mathrm{HCl}$ over $24 \mathrm{~h}$. Then, the samples were measured individually and filtered with $0.2 \mu \mathrm{m}$ Millipore filters and stored at $-78^{\circ} \mathrm{C}$ to measure the levels of urinary Creatinine $(\mathrm{Cr})$ levels. Then, all rats were anesthetized with light diethyl ether and $2 \mathrm{~mL}$ blood was collected directly by cardiac puncture, placed into plain tubes which was allowed to clot and then centrifuged at $5000 \mathrm{rpm}$ for $10 \mathrm{~min}$ at room temperature to collect serum. Serum samples were aliquoted and stored at $80^{\circ} \mathrm{C}$ for further analysis of urea, creatinine and total protein levels using commercial available kits according to manufacturer's instruction.

\subsection{Creatinine $(\mathrm{Cr})$ Clearance}

Cr clearance ( $\mathrm{Ccr}$ ) was calculated using the following equation (Liu et al., 2012):

Ccr $(\mathrm{mL} / \mathrm{min} / \mathrm{kg})=$ [urinary $\mathrm{Cr}(\mathrm{mg} / \mathrm{dL}) \times$ urinary volume $(\mathrm{mL}) /$ serum $\mathrm{Cr}(\mathrm{mg} / \mathrm{dL})] \times[1000 /$ body weight $(\mathrm{g})] \times[1 / 1440(\mathrm{~min})]$

\subsection{Preparation of Tissue Homogenates}

Immediately after blood collection, animals were killed by decapitation. Kidneys form all groups of were quickly collected, washed with Phosphate Buffered Saline (PBS), pH 7.4, containing $0.16 \mathrm{mg} \mathrm{mL}^{-1}$ of heparin to remove any red blood cells (erythrocytes) and clots. Then they were homogenized with an ultrasonic homogenizer in cold phosphate buffer, $\mathrm{pH} 7.0$ with Ethylenediaminetetraacetic Acid (EDTA), for Thiobarbituric Acid Reactive Substances (TBARS) measurement and with cold $20 \mathrm{mM} \mathrm{N}$-(2-hydroxyethyl) piperazine-N'-2-ethanesulfonic acid (HEPES) buffer, $\mathrm{pH}$ 7.2, containing $1 \mathrm{mM}$ ethyleneglycol-bis (2aminoethoxy)-tetraacetic acid (EGTA), $210 \mathrm{mM}$ mannitol and $70 \mathrm{mM}$ sucrose for SOD activity measurements. Also, other parts of the kindeys and livers were homogenized in cold buffer consists of $50 \mathrm{mM}$ tris$\mathrm{HCl}, \mathrm{pH} 7.5,5 \mathrm{mM}$ ED-TA, $1 \mathrm{nM}$ DTT for determination of Glutathione Peroxidase (GPx) activity and the levels of reduced Glutathione (GSH). All supernatants were kept in separate tubes and stored at20. However, other parts of the kidneys were placed in $10 \%$ formalin solution for histopathological evaluation.

\subsection{Measurement of Malondialdehyde (MDA) Levels}

Lipid peroxidation levels in the kindeny homogenates were measured by the Thiobarbituric Acid (TBA) reaction using the commercially available kits as per manufacture instructions. This method was used to measure spectrophotometrically the color produced by the reaction of TBA with Malondialdehyde (MDA) at $532 \mathrm{~nm}$. For this purpose, TBARS levels were measured using a commercial assay as the Malondialdehyde Assay (Cat No. NWK-MDA01) supplied from NWLSS, USA. In brief, Tissue supernatant $(50 \mu \mathrm{L})$ were added to test tubes containing $2 \mu \mathrm{L}$ of Butylated Hydroxytoluene (BHT) in methanol. Next, $50 \mu \mathrm{L}$ of acid reagent (1 M phosphoric acid) was added and finally $50 \mu \mathrm{L}$ of TBA solution was added. The tubes were mixed vigorously and incubated for $60 \mathrm{~min}$ at $60^{\circ} \mathrm{C}$. The mixture was centrifuged at $10,000 \times \mathrm{g}$ for $3 \mathrm{~min}$. The supernatant was put into wells on a microplate in aliquots of $75 \mu \mathrm{L}$ and its 
absorbance was measured with a plate reader at $532 \mathrm{~nm}$. MDA levels were expressed as nmol/mg protein.

\subsection{Measurement of Superoxide Dismutase (SOD) Activity}

SOD activitis in the kidneys homogenates were measured using the supplied commercially assay kit according to the manufacturer's instructions. The SOD assay consisted of a combination of the following reagents: $0.3 \mathrm{mM}$ xanthine oxidase, $0.6 \mathrm{mM}$ diethylenetriaminepenta acetic acid (DETAPAC), $150 \mu \mathrm{M}$ Nitroblue Tetrazolium (NBT), $400 \mathrm{mM}$ Sodium Carbonate (Na2CO3) and bovine serum albumin $\left(1 \mathrm{~g} \mathrm{~L}^{-1}\right)$. The principle of the method is based on the inhibition of NBT reduction by superoxide radicals produced by the xanthine/xanthine oxidase system. For the assay, standard SOD solutions and tissue supernatant $(10 \mu \mathrm{L})$ were added to wells containing $200 \mu \mathrm{L}$ of NBT solution that was diluted by adding 19.95 $\mathrm{mL}$ of $50 \mathrm{mM}$ Tris- $\mathrm{HCl}, \mathrm{pH} 8.0$, containing $0.1 \mathrm{mM}$ DETAPAC solution and $0.1 \mathrm{mM}$ hypoxanthine. Finally, 20 $\mu \mathrm{L}$ of xanthine oxidase was added to the wells at an interval of $20 \mathrm{~s}$. After incubation at $25^{\circ} \mathrm{C}$ for $20 \mathrm{~min}$, the reaction was terminated by the addition of $1 \mathrm{~mL}$ of $0.8 \mathrm{mM}$ cupric chloride. The formazan was measured spectrophotometrically by reading the absorbance at 560 $\mathrm{nm}$ with the help of plate reader. One Unit (U) of SOD is defined as the amount of protein that inhibits the rate of NBT reduction by $50 \%$. The calculated SOD activity was expressed as $\mathrm{U} / \mathrm{mg}$ protein.

\subsection{Measurement of Glutathione Peroxidase (GPx) Activity}

Glutathione peroxidase activities in kidneys homogenates were measured using the commercially supplied kit provided as per manufacture instructions. Glutathione peroxidase catalyzes the reduction of hydroperoxides, including hydrogen peroxide, by reduced glutathione and functions to protect the cell from oxidative damage. With the exception of phospholipid hydroperoxide GPX, a monomer, all of the GPX enzymes are tetramers of four identical subunits. Each subunit contains a selenocysteine in the active site, which participates directly in the two-electron reduction of the perox-ide substrate. The enzyme uses glutathione as the ultimate electron donor to regenerate the reduced form of the selenocysteine. The Cayman Chemical Glutathione Peroxidase Assay Kit measures GPx activity indirectly by a coupled reaction with Glutathione Reductase (GR). Oxidized Glutathione (GSSG) is produced upon reduction of hydroperoxide by GPX and is recycled to its reduced state by GR and NADPH. The oxidation of NADPH to NADP+ is accompanied by a decrease in absorbance at $340 \mathrm{~nm}$. Under conditions in which the GPX activity is rate limiting, the rate of decrease in the A340 is directly proportional to the GPX activity in the sample. The results were presented as $\mathrm{nmol} / \mathrm{min} / \mathrm{g}$ protein. One unit is defined as the amount odf enzyme that causing the oxidation of $0.1 \mathrm{nmol}$ of $\mathrm{NADPH}$ to $\mathrm{NADP}^{+} / \mathrm{min}$ at $25^{\circ} \mathrm{C}$.

\subsection{Glutathione Assay}

The levels of reduced GSH were measured using Cayman GSH assay kit which involved an optimized enzymatic recycling method and GR. The sulfhydryl group of GSH reacts with 5,5-ditho-bis-2-nitrobenzoic acid (DTNB) and produces yellow colored 5-Thio-2Nitrobenzoic Acid (TNB). A mixed disulfide, GSTNB (between GSH and TNB), is also produced that is reduced by GR to recycle GSH, thereby producing more TNB. The rate of TNB production is directly proportional to this recycling reaction which is in turn directly proportional to the concentration of GSH in the sample. The absorbance of TNB at $410 \mathrm{~nm}$ was used to estimate the amount of GSH in the sample. The GSH level was expressed as $\mu \mathrm{mol} / \mathrm{mg}$ protein.

\subsection{Histopathological Evaluation}

Kidney specimens from all groups of rats were processed routinely in $10 \%$ formalin solution and embedded in paraffin. Tissue sections of $5 \mu \mathrm{m}$ were obtained and stained with Hematoxylin and Eosin (H\&E). All histopathological examinations were performed under a light microscope (NIKON, Japan) by different histologist at the college of medicine at King Khalid University who was blinded to all tissue specimens regarding their group. A minimum of 10 fields for each kidney were examined.

\section{RESULTS}

\subsection{Changes in Body Weight, Kidney Weight and Food and Water Intake}

In all experimental groups, no mortality was observed during the period of the study. Significant reducedion $(p<0.0001)$ in water intake and food consumption, as we 11 as reduced total body and kidneys weight were observed in PCM group as compared to control (Fig. 1 and 2). In contrast, The group of rats received PCM concurrent with administration of $250 \mathrm{mg} \mathrm{kg}^{-1}$ of DHEA showed higher food and water consumption and weighed significantly higher and the weights of their kidneys were significantly higher $(\mathrm{p}<0.001)$ than corresponding levels seen in PCM Group. 


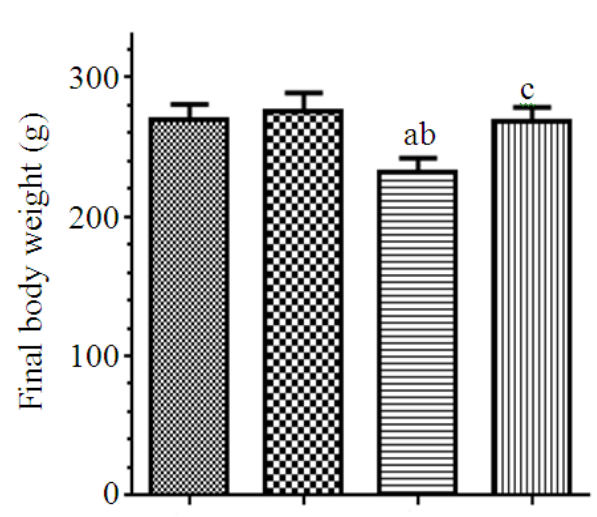

(a)

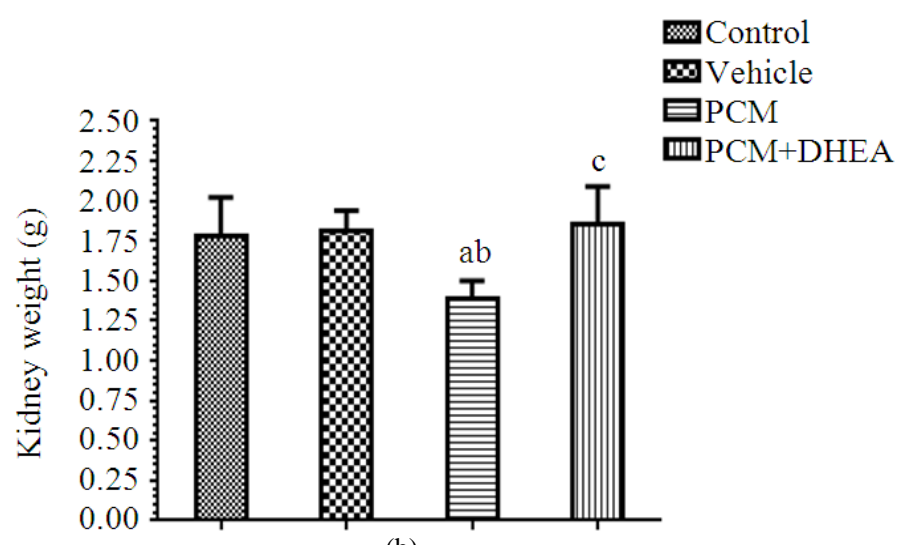

(b)

Fig. 1. Average final body and kidney weights in the control and experimental groups of rats. Values (mean \pm SD) were obtained for each group of 10 animals and considered significantly different at $\mathrm{p} \leq 0.05$. a: Significantly different when compared to control group; b: Significantly different when compared to vehicle treated group (5\% DMSO). c: Significantly different when compared to Paracetamol treated group (PCM)

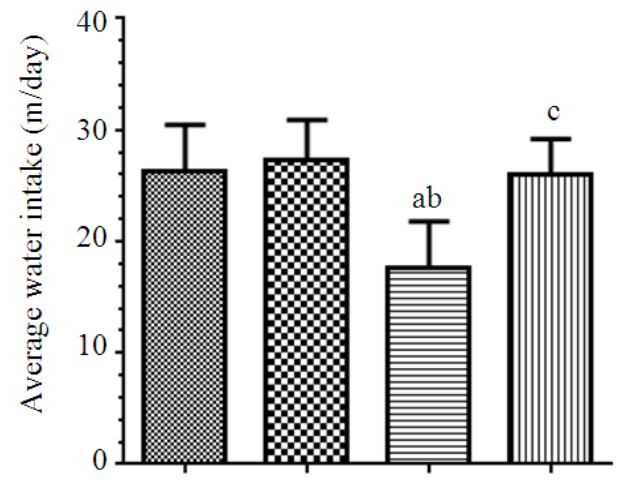

(a)

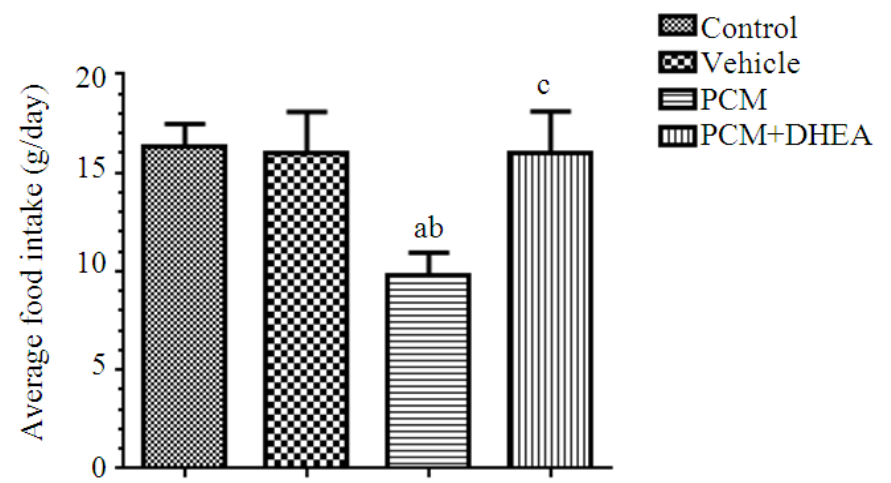

(b)

Fig. 2. Average daily food and water intakes in the control and experimental groups of rats. Values (mean \pm SD) were obtained for each group of 10 animals and considered significantly different at $\mathrm{p} \leq 0.05$. a: Significantly different when compared to control group; b: Significantly different when compared to vehicle treated group (5\% DMSO). c: Significantly different when compared to Paracetamol treated group (PCM)

ANOVA and Tukey's $\mathrm{T}$ test revealed no significant changes in the values of these parameters as compared to control group. Meanwhile, no significant alteration in water and food consumption, neither body or kidneys weight were recorded from rats treated with the vehicle alone (5\% DMSO).

\subsection{Markers of Kidney Function}

Indices of kidney functions were displayed in Table 1 and 2. The levels of BUN, urea and creatinine significantly $(\mathrm{p}<0.0001)$ increased where as total proteins levels were significantly decreased $(\mathrm{p}<0.0001)$ in serum of rats received paracetamol as compared to control group. Also, in these groups of rats and in concomitant with these findings, urine volume was significantly decreased resulting in significant decrease in $\mathrm{Cr}$ clearance $(\mathrm{p}<0.0001)$ On the other hand, rats administered vehicle alone (Group II) revealed a non-significant change in the mentioned parameters as compared to control group. However, co-treatment with DHEA and PCM recorded significant decrement in BUN $(\mathrm{p}<0.0012)$ urea $(\mathrm{p}<0.0021)$, creatinine $(\mathrm{p}<0.0032)$ as well as a aparallel significant increases in urine volume $(\mathrm{p}<0.0047)$ and serum total protein levels in comparison with paracetamol-treated group. The levels of all these parameters were not significantly different as compared to control group. 


\subsection{Oxidative Stress Parameters in the Renal Homogenates}

Activities of SOD and GPX as well as levels of GSH were significantly depressed $(\mathrm{p}<0.005)$ and levels of MDA were significantly enhanced $(\mathrm{p}<0.0003)$ in the renal homogenates of PCM treated group as compared to the control group. Meanwhile, no significant changes in the levels or activities in all of these parameters were
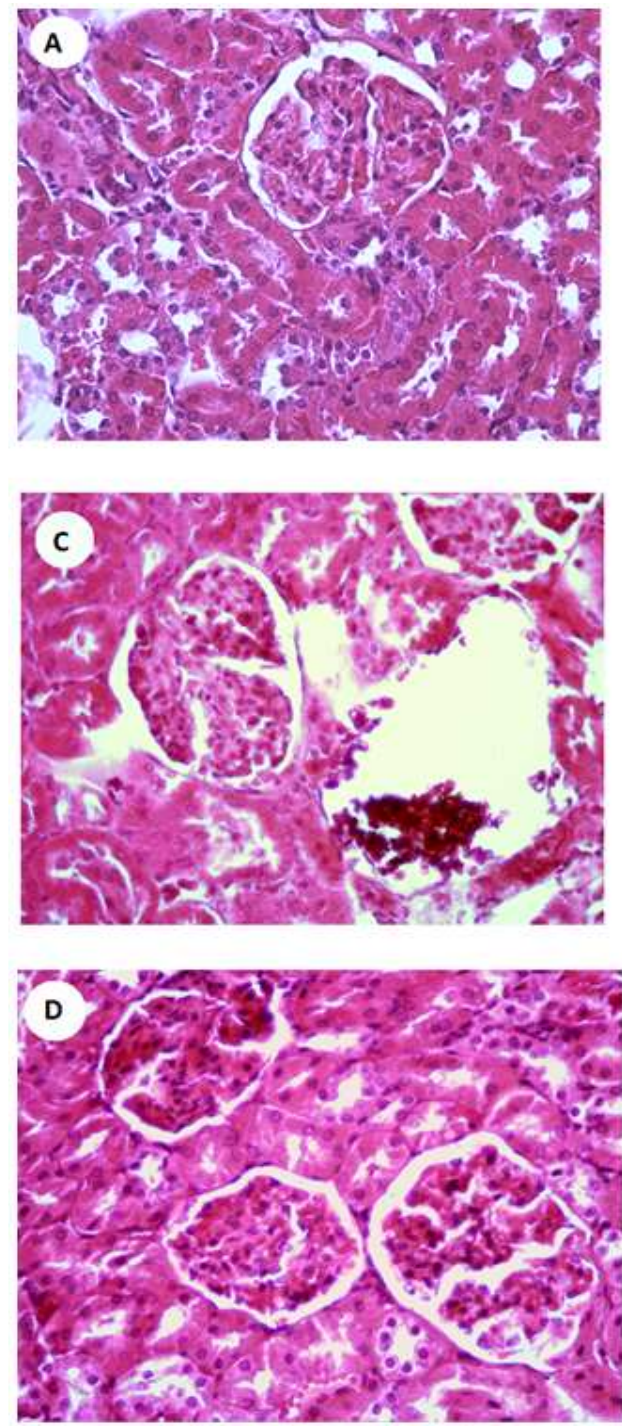

noticed in the renal tissue of the rats received vehicle. However, concomitant administration of DHEA to PCM intoxicated rats resulted in significant increases in the activities of SOD and GPX and in GSH levels and resulted in a significant decrease in MDA levels in their renal homogenates as compared to PCM treated rats. The ANOVA analysis showed no significant changes in the levels or activities of these parameters in this group of rats as compared to control group Table 3 .
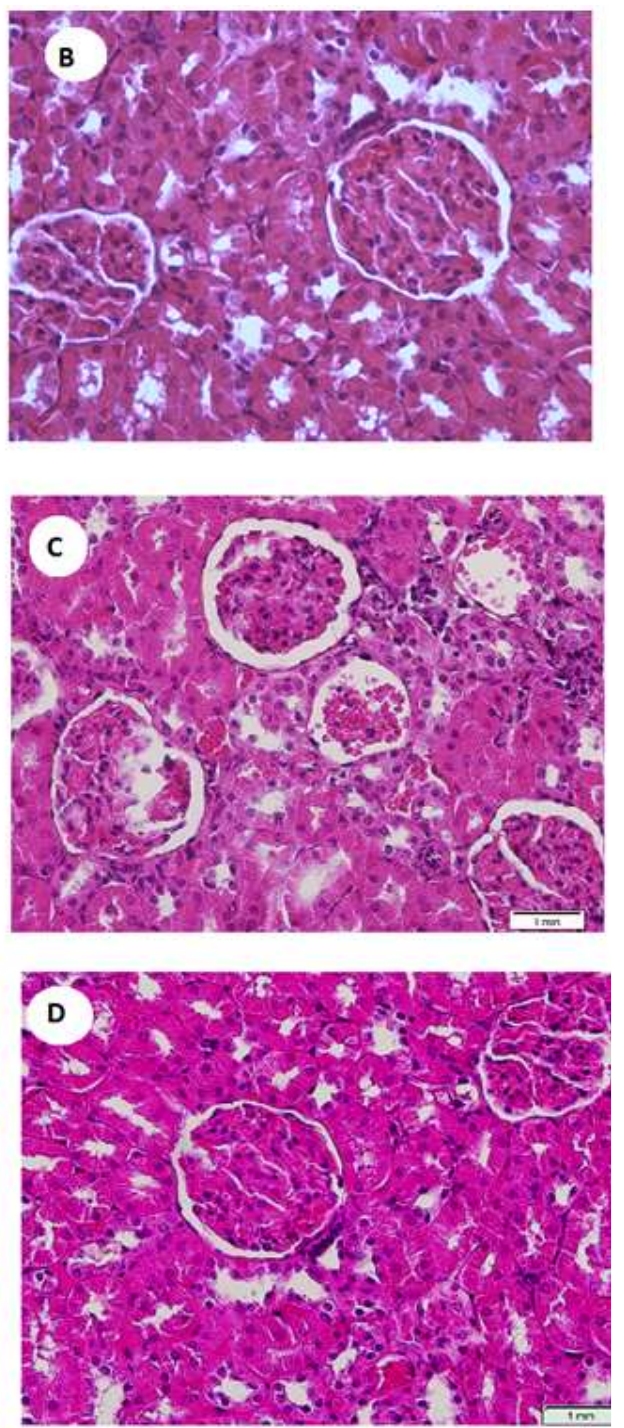

Fig. 3. Photomicrographs of kidneys from all groups of rats (A): Control rat. (B): DMSO treated rat, these groups show normal architecture of kidney with prominent Bowman's capsule, epithelial Cells and normal tubules. (C): Paracetamol (PCM) treated rat shows mild thickening of the basement membrane along with change in the density of mesenchyme, atrophy and degeneration of glomerular capillaries with increased Bowman's space (urinary space) and tubular necrosis. Glumerulular capillaries were completely absent in some glumerulus. (D): DHEA+ PCM treated rat shows normal archeticture of glomerular capillaries, intact epithelial cells with the presence of some degeneration in the tubules 
Abbas O. Elkarib / American Medical Journal 5 (1): 16-27, 2014

Table 1. Changes of the renal function-related parameters in the control and experimental groups of rats

\begin{tabular}{llllll}
\hline Group & BUN $(\mathrm{mg} / \mathrm{dL})$ & Serum Cr. $(\mathrm{mg} / \mathrm{dL})$ & Urinary Cr. $(\mathrm{mg} / \mathrm{dL})$ & Urine volume $(\mathrm{mL} / 24 \mathrm{~h})$. & $\mathrm{Ccr} .(\mathrm{mL} / \mathrm{min} / \mathrm{kg})$ \\
\hline Control & $16.01 \pm 2.34$ & $0.391 \pm 0.032$ & $59.63 \pm 2.67$ & $4.67 \pm 0.636$ & $1.98 \pm 0.595$ \\
Vehicle & $15.99 \pm 3.11$ & $0.388 \pm 0.041$ & $60.11 \pm 4.11$ & $4.91 \pm 0.316$ & $2.01 \pm 0.31$ \\
PCM & $28.61 \pm 3.78^{\mathrm{ab}}$ & $0.98 \pm 0.016^{\mathrm{ab}}$ & $19.61 \pm 2.46^{\mathrm{ab}}$ & $1.10 \pm 2.11^{\mathrm{ab}}$ & $0.064 \pm 0.024^{\mathrm{ab}}$ \\
PCM+DHEA & $18.59 \pm 3.45^{\mathrm{c}}$ & $0.403 \pm 0.011^{\mathrm{c}}$ & $57.65 \pm 5.16^{\mathrm{c}}$ & $4.88 \pm 0.83^{\mathrm{c}}$ & $1.94 \pm 0.085^{\mathrm{c}}$ \\
\hline
\end{tabular}

Values (mean \pm SD) were obtained for each group of 10 animals and considered significantly different at $\mathrm{p} \leq 0.05$. a: Significantly different when compared to control group; b: Significantly different when compared to vehicle treated group (5\% DMSO). c: Significantly different when compared to Paracetamol treated group (PCM). Cr: Creatinine, Ccr: Creatinine clearance rate

Table 2. Levels of Urea and total proteins in the serum of control and all experimental groups

\begin{tabular}{lll}
\hline Group & Urea $(\mathrm{mg} / \mathrm{dL})$ & Total proteins $(\mathrm{mg} / \mathrm{dL})$ \\
\hline Control & $34.35 \pm 3.11$ & $5.66+0.16$ \\
Vehicle & $34.22 \pm 3.67$ & $5.89 \pm 0.79$ \\
PCM & $61.32 \pm 5.11^{\mathrm{ab}}$ & $3.67 \pm 0.87^{\mathrm{ab}}$ \\
PCM+DHEA & $38.28 \pm 5.61^{\mathrm{c}}$ & $5.89 \pm 0.35^{\mathrm{c}}$ \\
\hline
\end{tabular}

Values (mean \pm SD) were obtained for each group of 10 animals and considered significantly different at $p \leq 0.05$. a: Significantly different when compared to control group; b: Significantly different when compared to vehicle treated group (5\% DMSO). c: Significantly different when compared to Paracetamol treated group (PCM)

Table 3. Levels of MDA and GSH and activities of Superoxide Dismutase (SOD) and glutathione peroxidise (GPx) in the kidney homogenates of the control and experimental groups of rats

\begin{tabular}{lllll}
\hline & $\begin{array}{l}\text { MDA } \\
(\mathrm{nmoL} / \mathrm{mg})\end{array}$ & $\begin{array}{l}\text { GSH } \\
\mu \mathrm{m} / \mathrm{mg}\end{array}$ & $\begin{array}{l}\text { SOD } \\
(\mathrm{U} / \mathrm{mg})\end{array}$ & $\begin{array}{l}\text { GPx } \\
(\mathrm{mmol} / \mathrm{min} / \mathrm{mL})\end{array}$ \\
\hline Control & $0.839 \pm 0.014$ & $44.33 \pm 3.45$ & $8.56 \pm 1.47$ & $65.14+3.64$ \\
Vehicle & $0.826 \pm 0.009$ & $46.32 \pm 5.46$ & $8.48 \pm 1.26$ & $65.884 \pm 6.13$ \\
PCM & $1.768 \pm 0.0 .041^{\mathrm{ab}}$ & $25.67 \pm 5.71^{\mathrm{ab}}$ & $5.15 \pm 0.914^{\mathrm{ab}}$ & $41.22 \pm 4.18^{\mathrm{ab}}$ \\
PCM+DHEA & $0.798 \pm 0.02^{\mathrm{c}}$ & $41.56 \pm 4.32^{\mathrm{c}}$ & $7.98 \pm 1.34^{\mathrm{c}}$ & $57 \pm 4.56^{\mathrm{c}}$ \\
\hline
\end{tabular}

Values (mean \pm SD) were obtained for each group of 10 animals and considered significantly different at $\mathrm{p} \leq 0.05$. a: Significantly different when compared to control group; b: Significantly different when compared to vehicle treated group (5\% DMSO). c: Significantly different when compared to Paracetamol treated group (PCM)

\subsection{Histopathogical Findings of Liver and Kidney}

Histology of kidney in the control or vehicle treated rats showed normal structure. In PCM treated rats, kidney sections showed mild thickening of the basement membrane along with mild change in the density of mesenchyme, atrophy and degeneration of glomerular capillaries with increased Bowman's space (urinary space) and mild tubular necrosis. Some of the glomerulular capillaries were completely absent. The group of rats administered PCM and DHEA showed improvement in their histological architectures including normal glomerulus, normal basement membrane and capillaries. Moreover, Bowman's space (urinary space) and Acute Tubular Necrosis (ATN) were improved towards normal condition Fig. 3 .

\section{DISCUSSION}

In the present study orally administered DHEA was subjected to nephro-protective activity by using
Paracetamol (PCM) induced nephrotoxicity model of rats. Biochemical markers of kidney function renal levels of antioxidant system components as well as lipid peroxidation and histopathological changes were considered for assessing its nephroprotective properties. The major findings of the current study are that orally administered DHEA (250 mg kg $\mathrm{kg}^{-1}$ ameliorated all biochemical parameters of nephrotoxicty and boosted renal endogenous non enzymatic and enzymatic antioxidant defence systems and resulted in mitigation of pathological changes in the kidney tissues of PCM intoxicated rats.

PCM induced nephrotoxicity has been previously documented by a number of studies (Chengxiu et al., 2003; Khorsandi and Orazizadeh, 2008; Fouad et al., 2009). However, srum urea, protein and creatinine as well as urinary creatinine levels are considered markers of nephrotoxicity, but serum urea concentration and the calculated creatinine clearance rate are often considered a more reliable renal function predictor than serum creatinine (Khorsandi and Orazizadeh, 2008). In this study, we demonstrated that the administration of 
overdose PCM (750 mg kg-1) for 28 consecutive days was able to induce nephrotoxicity in rats, as demonstrated by the significantly increased level of plasma urea and creatinine and significant decreases in serum total proteins. These results are in agreement with that observed by Isik et al. (2006) who noticed an elevation in serum urea and creatinine in rats after $1 \mathrm{~g} \mathrm{~kg}^{-1}$ b.w. of PCM administration. Moreover, Satirapoj et al. (2009) reported an elevation in serum urea and creatinine in a woman following therapeutic dose of PCM three days before hospital admission. Also, Our finding were in accordance with that reported by (Mayne, 1994) who has confirmed that in nephrotoxicity and renal diseases, the serum urea and creatinine accumulates because the rate of production exceeds the rate of clearance due to the defect in renal function. Indeed, supporting to this, in our current study, creatinine clearance was significantly reduced in the PCM administered rats.

The significant decreases in serum protein levels in PCM intoxicated rtas could be explained by excess secretion in the urine. One limitation of this in the current study is that we didn't measure protein level in the urine sample of these rats. These results are in agreement with that observed by Melo et al. (2006) who noticed an increase in the urinary excretion of albumin after PCM injection associated with decrease levels of serum protein. The decrease in protein levels in the serum of these rats may be attributed to the dysfunction of the proximal convoluted tubule because proteins are completely absorbed from these tubules under normal conditions.

The kidneys are involved in the excretion of various xenobiotics, pollutants, toxins and hence they are prone to liberate high quantities of free radicals which contribute to high oxidative stress that is involved in the pathogenesis of kidney damage (Ghosh et al., 2010). To date, a number of studies have suggested the involvement of oxidative stress as the mediator of PCM induced nephrotoxicity (Das et al., 2010; Yousef et al., 2010). Hart et al. (1994) pointed out that PCM toxicity was shown to enhance N-Acetyl-P-benzoquinone Imine (NAPQI) radicals production. The accumulated NAPQI induces greater formation of free radicals, which are responsible in mediating cellular damages and renal toxicity. It has been suggested suggests that the administration of high dose of PCM saturates the metabolic pathway, decreases the liver clearance of PCM and allows higher amounts of the un-metabolized drug to come in contact with the kidney (Gu et al., 2005). Because the same enzyme system as the liver is also present in the kidney, it is most probable that NAPQI will also be formed in the kidneys, giving rise to toxicity but much later than in the liver (Roberts and Bukley,
2007). In the kidneys, NAPQI in its high amounts will in turn be conjugated with GSH to detoxify this product with consequent exhaustion of cellular GSH reserve (Sener et al., 2005). At sufficiently high doses, GSH becomes depleted leaving NAPQI free (Dai et al., 2006). The free NAPQI is strongly electrophilic and binds covalently and irreversibly to critical cellular, protein causing cellular necrosis (James et al., 2003b). Also, elevated levels of MDA in tissue have been regarded as an indicator for cellular damage due to excess lipid peroxidation processes that occur during malfunction of the antioxidant defense system (Kaplowitz, 2000). Indeed, several studies have clearly demonstrated that PCM overdose induces renal oxidative stress as manifested by a decrease in antioxidant enzymes and an increase in lipid peroxidation product (malondialdehyde) (Ghosh and Sil, 2007).

The present study demonstrated that PCM overdose resulted in an increase in the renal MDA level paralleled with the decrease in the SOD and CAT activities as well as GSH level when compared with control rats. Our results were in agreement with that reported by Cohen et al. (1998) who concluded that PCM induced oxidative stress results in lipid peroxidation, protein thiols oxidation, depletion of antioxidant enzyme and mitochondrial endoplasmic reticulum injury. In the same line, Linares et al. (2006) suggested that, during renal injury and inflammation, superoxide and peroxide radicals are generated at the site of damage, resulting in the depletion of SOD and CAT activities which are considered the most important enzymes involved in ameliorating the effects of oxygen metabolism.

The nephrotoxic effect of PCM was further confirmed by the severely destructed renal tissue, as shown in the histological analysis of the kidneys of PCM intoxicated rats. PCM administered the overdose of PCM showed typical nephrotoxicty which is characterized by mild thickening of the basement membrane along with change in the density of mesenchyme, atrophy and degeneration of glomerular capillaries with increased Bowman's space (urinary space) and tubular necrosis. This finding is in accordance with that of Abdel-Zaher et al. (2007) who showed that the administration of PCM at $750 \mathrm{mg} \mathrm{kg}^{-1}$ induced nephrotoxicity and structural changes in the kidneys of rats.

The possibility of using DHEA in management of various diseases has attracted considerable attention over recent years. Whereas DHEA therapy seems to be effective in treating patients with cognitive decline, depression, cardiovascular disease, osteoporosis and 
sexual dysfunctions (Krysiak et al., 2008), in the current study, we sought to test the hypothesis that DHEA at its previously reported neuroprotective and cardiovascular protective dose $\left(250 \mathrm{mg} \mathrm{kg}^{-1}\right)$ could offer protection against PCM induced nephrotoxicity in rats. To our knowledge, this is the first report on the renal effects of chronic DHEA administration that shows beneficial effects of DHEA on the nephropathy of this model.

In the current study, concomitant oral administeration of DHEA with PCM ameliorated the nephrotoxic effect of PCM and resulted in normal levels of BUN, urea, creatinine and total proteins were seen in the serum of these intoxicated rats. The improvements in the levels of these kidney function markers could be attributed to the glomerular repair. Indeed, Histopathological sections taken from the kidneys of DHEA treated rats showed improvement in the kidney structure that looked almost normal as compared to the corresponding changes seen in the kidneys of PCM intoxicated rats. The nephroprotective effect of DHEA reported in our study is in agreement to many previous studies which shows that DHEA could offer nephroprotection in various diseases. Richards et al. (2001) reported nephrophroprotective effect of DHEA against nephropathy in obese rats.

Form the findings of our current study; it seems that the nephroprotective effect of DHEA is mainly due to its antioxidant activity. DHEA administration ameliorated the renal levels of GSH and resulted in normal activities of both SOD and CAT. Furthermore, the renal levels of lipid peroxides, MDA, were significantly reduced in DHEA treated rats as compared to PCM intoxicated rats. Our results are in the same line with Aragno et al. (1997; Boccuzzi et al., 1997) who reported that DHEA possesses antioxidant activity. Also, Kumar et al. (2008) have shown that the protective effects of DHEA in various disease condition are attributed to its antioxidant, anti-lipidperoxidative, anti-inflammatory and thereby anti-aging actions.

The mechanism underlying the protective effect of DHEA against oxygen free radical damage is still undefined and might implicate DHEA metabolism. Experiments performed by adding DHEA directly to either isolated microsomes or lipoproteins failed to exert any protective effect, throwing doubt on whether DHEA itself acts as a direct antioxidant (Boccuzzi et al. 1997). In rats, DHEA given i.p. $3 \mathrm{~h}$ before dextrose administration protects tissues against lipid peroxidation induced by hyperglycaemia, whereas a $1 \mathrm{~h}$ pre-treatment is ineffective (Aragno et al., 1997). Thus, DHEA does appear to need a 'lag-phase' before becoming active and it could be speculated that during this time it is converted into an active metabolite. Indeed, most effects of DHEA are mediated by one or other of its metabolites, such as 5en-androsten-3 $\beta, 17 \beta$ diol for the hormonal effect (Boccuzzi et al., 1994) or 5-en-androsten-3 $\beta, 7 \beta, 17 \beta$ triol for the action on the immune system (Padgett and Loria, 1994). The active compound (i.e., DHEA or one of its metabolites) might modify the structure or lipid composition of the cell membrane. A similar mechanism has been reported for another steroid hormone, i.e. oestradiol, which induces stable modifications of lipoproteins making them more resistant to attack by free radicals (Shwaery et al., 1997). Indeed, DHEA protects plasma Low Density Lipoprotein (LDL) against lipid peroxidation and is able to change the fatty acid composition of the phospholipid membrane of mitochondria in rats(Boccuzzi et al., 1997).

Also, It has been reported that the natural DHEAS is a specific activator of Peroxisome Proliferator-Activated Receptor $\alpha$ (PPAR $\alpha)$ (Peters et al., 1996). Activation of PPAR $\alpha$ in vivo causes an upregulation of mRNA and protein levels of a number of peroxisomal and nonperoxisomeassociated enzymes and structural proteins, among them the antioxidant enzymes CAT and $\mathrm{Cu}, \mathrm{Zn}$ superoxide dismutase, as well as mediators of the glutathione pathway (Devchand et al., 1996).

\section{CONCLUSION}

Whatever the mechanism, these results further confirm the multi-targeted antioxidant properties of DHEA reported in this study is considered one of the main mechanisms by which this hormone offers a protection against PCM induced nephrotoxicity in rats. However, one limitation of our study is that we didn't investigate the regulatory effect of DHEA on gene expression of the antioxidant enzymes. Also, as inflammation has been implicated to play an essential role in PCM nephrotoxicity, further studies on the anti-inflammatory effect of DHEA against PCM induced nephrotoxicity is required.

\section{REFERENCES}

Abdel-Zaher, A.O., M.M. Abdel-Rahman, M.M. Hafez and F.M. Omran, 2007. Role of nitric oxide and reduced glutathione in the protective effects of aminoguanidine, gadolinium chloride and oleanolic acid against acetaminophen-induced hepatic and renal damage. Toxicology, 234: 124134. DOI: 10.1016/j.tox.2007.02. 014 
Aksoy, Y., T. Yapanoglu, H. Aksoy and A.K. Yildirim, 2004. The effect of dehydroepiandrosterone on renal ischemia-reperfusion-induced oxidative stress in rabbits. Urol. Res., 32: 93-6. DOI: 10.1007/s00240003-0382-6

Aragno, M., E. Brignardello, E. Tamagno, V. Gatto and O. Danni et al., 1997. Dehydroepiandrosterone administration prevents thr oxidative damage induced by acute hyperglycemia in rats. J. Endocrinol., 155: 233-40. DOI: 10.1677/joe.0.1550233

Bernal, W., 2003. Changing patterns of causation and the use of transplantation in the United Kingdom. Seminars Liver Dis., 23: 227- 237. PMID:14523676

Bessems, J.G. and N.P. Vermeulen, 2001. Paracetamol (acetaminophen)-induced toxicity: Molecular and biochemical mechanisms, analogues and protective approaches. Critical Rev. Toxicol., 31: 55-138. DOI: 10.1080/20014091111677

Blakely, P. and B.R. McDonald, 1995. Acute renal failure due to acetaminophen ingestion: A case report and review of the literature. J. Am. Soc. Nephrol., 6: 48-53. PMID: 7579069

Boccuzzi, G., E. Brignardello, M. Di Monaco, V. Gatto and L. Leonardi et al., 1994. 5-en-androsten-3_,17_diol inhibits the growth of MCF-7 breast cancer cells when estrogen receptors are blocked by estradiol. British J. Cancer, 70: 1035-1039. DOI: PMC2033679

Boccuzzi, G., M. Aragno, E. Brignardello, E. Tamagno and G. Conti et al., 1992. Opposite effects of dehydroepiandrosterone on the growth of 7,12dimethyl-benz(a)anthracene-induced rat mammary carcinomas. Anticancer Res., 12: 1479-1484. PMID: 1444210

Boccuzzi, G., M. Aragno, N. Seccia, E. Brignardello and E. Tamagno et al., 1997. Protective effect of dehydroepiandrosterone against copper-induced lipid peroxidation in the rat. Free Rad. Biol. Med., 22: 1289-1294. PMID: 9098104

Boutis, K. and M. Shannon, 2001. Nephrotoxicity after acute severe acetaminophen poisoning in adolescents. Clin. Toxicol., 39: 441-445. DOI: 10.1081/CLT-100105413.

Brignardello, E., E. Beltramo, P.A. Molinatti, M. Aragno and V. Gatto, 1998. Dehydroepiandrosterone protects bovine retinal capillary pericytes against glucose toxicity. J. Endocrinol., 158: 21-26. DOI: 10.1677/joe.0.1580021
Carpenter, H.M. and G.H. Mudge, 1981. Acetaminophen nephrotoxicity: Studies on renal acetylation and deacetylation. J. Pharmacol. Exp. Ther., 218: 161167. PMID: 7241376

Chengxiu, L., J. Liu, J.E. Saavedra, L.K. Keefer and M.P. Waalkes, 2003. The nitric oxide donor, VPYRO/NO, protects against acetaminophen- induced nephrotoxicity in mice. Toxicology, 89: 173-180. PMID: 12832150

Cohen, S.D., D.J. Hoivik and E.A. Khairallah, 1998. Acetaminophen-Induced Hepatotoxicity. In: Toxicology of the Liver, Taylor and Francis, Plaa, G.L. and W.R. Hewitt (Eds.,), Philadelphia, pp: 159-186.

Coleman, D.L., E.H. Leiter and R.W. Schwizer, 1982 Therapeutic effects of Dehydroepiandrosterone (DHEA) in diabetic mice. Diabetes, 31: 830-833. PMID: 6219024

Dai, G., L. He, N. Chou and Y. Wan, 2006. Acetaminophen metabolism does not contribute to gender difference in its hepatotoxicity in mouse. Toxicol. Sci., 92: 33-41. DOI: 10.1093/toxsci/kfj192

Das, J., J. Ghosh, P. Manna and P.C. Sil, 2010. Taurine protects acetaminophen-induced oxidative damage in mice kidney through APAP urinary excretion and CYP2E1 inactivation. Toxicology, 269: 24-34. DOI: 10.1016/j.tox.2010.01.003

Devchand, P.R., H. Keller, J.M. Peters, M. Vazquez and F.J. Gonzalez et al., 1996. The PPAR $\alpha$-leukotriene B4 pathway to inflammation control. Nature, 384: 39-43. PMID: 8900274

Elhabib, E.M., M.M.A. Homeida and S.E.I. Adam, 2007. Effect of combined paracetamol and cuminum cyminum and nigella sativause in wistar rats. J. Pharmacol. Toxicol., 2: 653-659. DOI: 10.3923/jpt.2007.653.659

Fouad, A.A., M.T. Yacoubi and M.H. El-Bidawy, 2009. Therapeutic potential of hemin in acetaminophen induced nephrotoxicity in rats. Envoiron. Toxicol. Pharmacol., 27: 277-282. DOI: 10.1016/j.etap.2008.11.002

Ghosh, A. and P.C. Sil, 2007. Anti-oxidative effect of a protein from Cajanusindicus $\mathrm{L}$ against acetaminophen-induced hepato-nephrotoxicity. J. Biochem. Mol. Biol., 40: 1039-49. PMID: 18047802

Ghosh, J., J. Das, P. Manna and P.C. Sil, 2010. Acetaminophen induced renal injury via oxidative stress and TNF-alpha production: therapeutic potential of arjunolic acid. Toxicology, 268: 8-18. DOI: 10.1016/j.tox.2009.11.011 
Gordon, G.B., D.E. Bush and H.F. Weisman, 1988. Reduction of atherosclerosis by administration of DHEA. J. Clin. Inv., 82: 712-720. DOI: 10.1172/JCI113652

Gu, J., H. Cui, L. Zhang, Q. Zhang and W.Yang et al., 2005. In vivo mechanisms of tissue-selective drug toxicity: Effects of liver-specific knockout of the NADPH-cytochrome $\mathrm{P} 450$ reductase gene on acetaminophen toxicity in kidney, lung and nasal mucosa. Mol. Pharmacol., 67: 623-30. PMID: 15550675

Gulnaz, H., M. Tahir, B. Muni and W. Sami, 2010. Protective effects of garlic oil on acetaminophen induced nephrotoxicity in male Wistar rats. Biomedica, 26: 9-15.

Hart, S.G., W.P. Beierschmitt, D.S. Wyand E.A. Khairallaha and S.D. Cohen, 1994. Acetaminophen nephrotoxicity in CD-1 mice. I. Evidence of a role for in situ activation in selective covalent binding and toxicity. Toxicol. Appl. Pharmacol., 126: 267-275. DOI: 10.1006/taap.1994. 1116

Isik, B., R. Bayrak, A. Akcay and S. Sogut, 2006. Erdosteine against acetaminophen-induced renal toxicity. Mol. Cell Biochem., 287: 185-91. DOI: 10.1007/s11010-005-9110-6

Jalan, R., R. Williams and J. Bernuau, 2006. Comment: Paracetamol: Are therapeutic doses entirely safe. Lancet, 368: 2195-2196. PMID: 17189017

James, L.P., P.R. Mayeux and J.A., Hinson, 2003a. Acetaminophen-induced hepatotoxicity. Drug Metabolism Disposit., 31: 1499-1506. DOI: 10.1124/dmd.31.12.1499

James, L.S., L. McCullough and L.J. Hinson, 2003b. Effect of $\mathrm{N}$-acetylcysteine on acetaminophen toxicity in mice: Relationship to reactive nitrogen and cytokine formation. Toxicol. Sci., 75: 458-67. DOI: $10.1093 /$ toxsci/kfg181

Kaplowitz, N., 2000. Mechanism of liver cell injury. J. Hepatol., 32: 39-47.

Khorsandi, L. and M. Orazizadeh, 2008. Protective effects of Curcuma longa extract on acetaminophen induced neph-rotoxicity in mice. DARU, 16: 155159.

Krysiak, R., D. Frysz-Naglak and B. Okopie, 2008. Current views on the role of dehydroepiandrosterone in physiology, pathology and therapy. Pol. Merk. Lek., 24: 66-71. PMID: 18634257
Kumar, P., A. Taha, D. Sharma, R.K. Kale and N.Z. Baquer, 2008. Effect of dehydroepiandrosterone (DHEA) on monoamine oxidase activity, lipid peroxidation and lipofuscin accumulation in aging rat brain regions. Biogerontol, 9: 235-246.

Lardy, H., S.M. Henwood and C.E. Weeks, 1999. An acute oral gavage study of $\beta$-acetoxyandrost-5-ene7, 17-dione (7-oxo-DHEA-acetate) in rats. Biochem. Biophys. Res. Commun., 254: 120-123. PMID: 9920743

Linares, M.V., M. Bellés, M.L. Albina, J.J. Sirvent and D.J. Sanchez, 2006. Assesment of the pro-oxidant activity of uranium in kidney and testis of rats. Toxicol. Lett., 167: 52-61. PMID: 17069995

Liu, X., S. Ramirez, P.T. Pang, C.B. Puryear, and A. Govindarajan et al., 2012. Optogenetic stimulation of a hippocampal engram activates fear memory recall. Nature, 484: 381-385. DOI: 10.1038 /nature 11028

Marieb, E., 2006. Urinary System. In: Essentials of Human Anatomy and Physiology, Pearson Benjamin Cummings, San Fransisco, Boston, New York, London and Madrid ip, pp: 501-26.

Mayne, P.D., 1994. The Kidneys And Renal Calculi. In: Clinical Chemistry in Diagnosis and Treatment, Mayne, P., J.F. Zilva, and P. Ronald Pannall (Eds.)., Edward Arnold Publications, London, ISBN-10: 0340576472,pp: 2-24.

Melo, D., V. Sociura, J. Poloni, C. Oliveira and J. Filho et al., 2006. Evaluation of renal enzymuia and cellular excretion as a marker of acute nephrotoxicity by APAP overdose in Wistar rats. Clin. Chem. Acta, 373: 88-91. PMID: 16806140

Nestler, J.E., C.O. Barlascini, J.N. Clore and W.G. Blackard, 1988. Dehydroepiandrosterone reduces serum low density lipoprotein levels and body fat, but does not alter insulin sensitivity in normal man. J. Clin. Endocrinol. Metabolism, 66: 57-71. PMID: 2961787

Nourjah, P. and M. Wiley, 2002. Epidemiology of acetaminophen-related overdose. Department of Health and Human Services, Center for Drug Evaluation and Research, Food and Drug Administration.

Ozkaya, O., G. Genc, K. Bek and Y. Sullu, 2010. A case of acetaminophen (paracetamol) causing renal failure without liver damage in a child. Renal Failure, 32: 1125-1127. PMID: 20863222 
Padgett, D. and R. Loria, 1994. In vitro potentiation of lymphocyte activation by dehydroepiandrosterone androstenediol and androstenetriol. J. Immunol., 153: 1544-1552. PMID: 8046232

Peters, J.M., Y.C. Zhou, P.A. Ram, S.S.T. Lee and F.J. Gonzalez et al., 1996. Peroxisome proliferatorsactivated receptor $\alpha$ required for gene induction by ehydroepiandrosterone-3- $\beta$-sulfate. Mol. Pharmacol., 50: 67-74. DOI: 0026-895X/96/010067

Richards, R.J., J.R. Porter, F. Inserra, L.F. Ferder, I. Stella and E. Reisin et al., 2001. Effects of dehydroepiandrosterone and quinapril on nephropathy in obese Zucker rats. Kidney Int., 59: 37-43. DOI: 10.1046/j.1523-1755.2001.00463.x

Roberts, D. and N. Buckley, 2007. Pharmacokinetic considerations in clinical toxicology: Clinical Applications. Clin. Pharmacokinet., 46: 897-939. DOI: 10.2165/00003088-200746110-00001

Satirapoj, B., P. Lohacit and T. Ruamvang, 2009. Therapeutic dose of acetaminophen with fatal hepatic necrosis and acute renal failure. J. Med. Assoc. Thai., 90: 1244-47. PMID: 17624227

Schnellman, R.G., 2001. Toxic Responses of Thekidneys. In: Casarett and Doull's Toxicology: The Basic Science of Poisons, McGraw-Hill Medical Division, New York, pp: 491-514.

Sener, G., A. Sehirli and G. Ayanog lu-Dülger, 2003. Protective effects of melatonin, vitamin E and Nacetylcysteine against acetaminophen toxicity in mice. A comparative study. J. Pineal. Res., 35: 6168. DOI: 10.1034/j.1600-079X.2003.00050.x

Sener, G., O. Sehirli, S. Cetinel, B. Yegen and N. Gedik et al., 2005. Protective effects of MESNA (2mercaptoethane sulphonate) against APAP hepatorenal oxidative damage in mice. J. Applc. Toxicol., 25: 20-9. PMID: 15669031
Shwaery, G.T., J.A. Vita and J.F. Keaney, 1997. Antioxidant protection of LDL by physiological concentrations of 17-estradiol. Requirement for estradiol modification. Circulation, 95: 13781385. DOI: 10.1161/01.CIR.95.6.1378

Stern, S., M. Bruno, G. Hennig, R. Horton and J. Roberts et al., 2005. Contribution of acetaminophen- cysteine to acetaminophen nephrotoxicity in CD-1 mice. 1. Enhancement of acetaminophen nephrotoxicity by acetaminophencysteine. Toxicl. Appl. Pharmacol., 202: 151-9. DOI: 10.1016/j.taap.2004.06.030

Toklu, H.Z., A.O. Sehrili, A.V. Ogunc, S. Cetinal and G. Sener, 2006. Acetaminophen-induced toxicity is prevented by $\beta$-dglucan treatment in mice. Eur. J. Pharmacol., 543: 133-40. DOI: 10.1016/j.ejphar.2006.05.033

Yousef, M.I., S.A. Omar, M.I. El-Guendi and L.A. Abdelmegid, 2010. Potential protective effects of quercetin and curcumin on paracetamol-induced histological changes, oxidative stress, liver and kidney functions and haematotoxicity in rat. Food Chem. Toxicol., 48: 3246-3261. PMID: 20804811

Zariyantey, A., B.B. Siti, Q.J. Ng, H. Asmah and M.H. Jamaludin, 2012. Nephroprotective effects of Zingiber zerumbet Smith ethyl acetate extract against paracetamol-induced nephrotoxicity and oxidative stress in rats. Zhejiang Univ. Sci. B., 13: 176-185. DOI: 10.1631/jzus.B1100133 